\title{
LA COMUNICACIÓN COMO TÁCTICA DE LA ESTRATEGIA EMPRESARIAL
}

\section{Magdalena Mut Camacho}

Universitat Jaume I de Castellón

Durante mucho tiempo, en la empresa, tuvo un papel hegemónico la comunicación publicitaria. El siglo XX trajo el gran desarrollo de la comunicación de masas, de los grandes medios de comunicación, y con ellos el desarrollo de la publicidad como instrumento fundamental del crecimiento espectacular de la producción y el consumo.

Esta nueva situación dio lugar a un conocimiento empírico y a algunas reflexiones académicas sobre la comunicación empresarial. Como forma dominante y única de comunicación la empresa utilizaba la publicidad y otras acciones que se llamaron relaciones públicas de un modo muy genérico y que a veces exigía la utilización de técnicas y medios periodísticos, pero en ningún caso se atendían los intereses de la audiencia, de los ciudadanos ${ }^{1}$.

Esta situación de la comunicación empresarial fue evolucionando a lo largo del pasado siglo, pero básicamente mantuvo sus principios sin que se produjeran excesivos cambios conceptuales. Incluso en nuestros días todavía hay personan que siguen identificando la comunicación con un instrumentos más del marketing, cuando no un puro adorno, una voluta en el capitel o la guinda final en el pastel de nuestra empresa. Pero esta situación tradicional, que muchos siguen considerando válida, está dando paso a una nueva interpretación radicalmente diferente, en la que la comunicación ha dejado de ser la guinda para convertirse en un ingrediente básico; la comunicación deja de ser accesoria para convertirse en gestión empresarial, y de su presencia, de su utilización, dependerá no ya el éxito o el fracaso de nuestra empresa, sino su propia existencia.

En ese sentido, las condiciones impuestas por la economía de mercado han conducido a variar la consideración acerca de la información y la comunicación. Los empresarios han constatado que la información es un factor clave en el proceso productivo, puesto que de ella dependen todas las decisiones, sea en la producción, las finanzas, la comercialización o la gestión del personal ${ }^{2}$. Esto ha comportado administrar el flujo informativo del mismo modo que otros recursos estratégicos.

1. ¿Hay "otra" comunicación?

En un principio, la comunicación en las empresas era una herramienta que tan sólo se utilizaba con un objetivo funcional. Donde los cometidos que ésta desempeñaba,

\footnotetext{
${ }^{1}$ BENAVIDES J. (ed.) El director de Comunicación. Edipo. Madrid, 1992. Pag. De Javier Sánchez del Moral.

${ }^{2}$ SOTELO, C. Introducción a la comunicación institucional. Ariel Comunicación. Barcelona, 2001. Pág. 8.
} 
para lo cual seguimos a Thayer ${ }^{3}$ y Ruiz Olabuénaga ${ }^{4}$, podían ser: funciones informativa, de mando y de instrucción, de influencia o de motivación, integrativas o integradoras, de transmisión de la cultura, de legitimación, de identidad, pedagógica, tecnológica y política.

En esta misma línea, según Simon ${ }^{5}$, no puede existir una organización sin comunicación porque en este caso no hay posibilidad de que el grupo influya sobre el individuo. Por su parte, Katz y $\mathrm{Khan}^{6}$ consideran que las comunicaciones, el intercambio de información y la transmisión de significado, son la esencia misma de un sistema social o de una organización. Según Hall ${ }^{7}$ la importancia de la comunicación varía de acuerdo con la dirección hacia donde se esté mirando en una organización y el tipo de organización que se está estudiando.

En definitiva, la comunicación únicamente era considerada como un proceso de transmisión y recepción de mensajes entre emisores y destinatarios a través de canales determinados y con códigos establecidos para conseguir la asunción de dichos mensajes (Davis y Newstrom, 1991; Bartoli, 1992; Costa, 1995; Koontz y Weihrich, 1995; Justicia, 1996) ${ }^{8}$.

Sin embargo, en los últimos años, el debate sobre la comunicación ha derivado hacia una perspectiva estratégica, convirtiéndose además en una gestión autónoma, independiente, propiciadora del cambio y correctora del cambio. La comunicación ha entrado en la empresa en su más amplio sentido, abarcando a toda la organización e integrándose en ella desde los cimientos. Tal como Costa ${ }^{9}$ refiere, al señalar ésta como el sistema nervioso de las organizaciones. En el mismo sentido en el que Hargie, Dickson y Tourish ${ }^{10}$ se refieren a la misma, como el oxígeno de la organización, el sistema nervioso central, las arterias, el combustible que hace funcionar la maquinaria, etc. También Arrieta considera a la comunicación en empresa como el «sistema nervioso de la empresa o institución ${ }^{11}$ ».

La comunicación entendida como Costa precisa en sus estudios: con «comunicación» no nos referimos a los mensajes cuyo objeto obvio es comunicar, sino a todos aquellos estímulos diversos que actúan como tales en el discurso de

\footnotetext{
${ }^{3}$ THAYER, L. Comunicación y sistemas de comunicación. Península. Barcelona, 1975.

${ }^{4}$ RUIZ OLABUÉNAGA, J. I. Sociología de las organizaciones. Universidad de Deusto. Bilbao, 1995.

${ }^{5}$ SIMON, H. A. El comportamiento administrativo. Estudio de los procesos de decisiones en la organización administrativa. Aguilar. Madrid, 1971

${ }^{6}$ KATZ, D. y KAHN, R.L. Psicología social de las organizaciones. Trillas. Madrid, 1981.

${ }^{7}$ HALL, R.H. Organizaciones: estructura y proceso. Prentice Hall. Madrid, 1983.

${ }^{8}$ DAVIS, K y NEWSTROM, J. W. El comportamiento humano en el trabajo. Comportamiento organizacional. McGraw Hill. México, 1991. BARTOLI, A. Comunicación y organización. Paidós. Barcelona, 1992. COSTA, J. Comunicación corporativa y revolución de los servicios. Ciencias Sociales. Madrid, 1995. KOONTZ, H y WEIHRICH, H. Administración. Una perspectiva global. McGraw Hill. México, 1995. JUSTICIA, A. "Comunicación interna y competitividad" Telos. Cuadernos de Comunicación, tecnología y sociedad. № 177, junio agosto, 1996.

${ }^{9}$ COSTA, J. Comunicación corporativa y revolución de los servicios. Ciencias Sociales. Madrid, 1995.

${ }^{10}$ HARGIE, W.D.W., DICKSON, D. y TOURISH, D. Communication in management. Gower. Vermont, 1999.

${ }^{11}$ ARRIETA, L. "La dimensión del propósito en la Comunicación Organizacional". La comunicación Empresarial. Tarea de profesionales. ASECOM. Madrid, 1989. Pág. 141.
} 
una empresa. Esto significa que la empresa se dirige y se relaciona con sus públicos directos e indirectos, que se encuentran diseminados en el campo social. Por un lado, envía una serie de mensajes, que han sido cuidadosamente planeados, elaborados, pretesteados y finalmente difundidos a través de los medios de masas. Son mensajes voluntariamente elaborados y propagados. Por otro lado, y al mismo tiempo, otra clase de mensajes selectivos, personalizados, o interpersonales, van también de la empresa al campo social a través del contacto con las personas, a través de los micromedia y de las acciones, los actos y los hechos.

De este modo, entra en la escena la Comunicación Corporativa como germen de una nueva estrategia de las organizaciones. La comunicación se ha convertido en «corporativa», no por un capricho del lenguaje ni por querer introducir más complejidad en el mundo de las empresas, sino por la fuerza de las cosas. Es en muchos casos por este motivo, como señala Costa, que hayan pillado impreparadas a las organizaciones ante una nueva realidad emergente que es ella misma producto de la complejidad generalizada y de la saturación tecnológica que caracterizan nuestra sociedad y nuestra civilizaron ${ }^{12}$. Para explicar ese significado tan importante de la comunicación, hay autores que incluso consideran a la comunicación más que una «herramienta», una «metaherramienta».

2. De la comunicación entendida como herramienta a convertirse en estrategia

La comunicación es herramienta cuando se trata como un simple instrumento más dentro de la gestión empresarial con el objetivo de servir de forma secundaria a la transmisión eficaz y positiva de los objetivos marcados por la estrategia de la empresa. Esta forma instrumental de comprender la comunicación, hace que se asimile no como un absoluto inamovible, sino como la maleable función para lograr construir la imagen adecuada y para mantener la empresa comunicada con sus públicos prioritarios. Por tanto, la Comunicación Corporativa será el instrumento adecuado para ciertas tareas, en ciertas condiciones y en ciertos momentos, que hasta hace un tiempo no se tenían en cuenta y se desconocían sus potenciales. Costa explica este proceso e introduce el concepto de «ecología de la comunicación» para explicar este aspecto de la comunicación. A partir del concepto ecología de la comunicación, se ha empezado a comprender que la comunicación no es sólo un conjunto de técnicas, medios y mensajes que más o menos traban en coordinación. Se va comprendiendo también que un concepto «ecológico» es un concepto vivo, y que siguiendo sus leyes, los diferentes instrumentos de la comunicación aumentan o reducen su acción relativa dentro del conjunto en función de las necesidades. Estos no son estáticos ni siempre actúan todos, ni todos a la vez. ${ }^{13}$ La comunicación corporativa es la punta del iceberg de una nueva mentalidad holista, pero que las mismas empresas ignoran todavía, porque está en trance de

\footnotetext{
${ }^{12}$ COSTA, J. Imagen corporativa en el siglo XXI. La crujía. Buenos Aires, 2001. Pág. 95.

${ }^{13}$ COSTA, J. Comunicación corporativa y revolución de los servicios. Ciencias sociales. Madrid, 1995. Pág. 228.
} 
formarse. La comunicación corporativa es hoy el núcleo de lo que pronto será el "espíritu corporativo".

La comunicación es herramienta de una gestión empresarial que se ha integrado en la era de la información y que ha de ser entendida como Drucker propone en su paradigma para el nuevo siglo en el que estamos: hay que detenerse en definir y matizar la «gestión» alejándola de «empresarial» para centrar tan sólo sobre ella toda la importancia que posee en sí misma. En consecuencia, la gestión existe por causa de los resultados de la institución. La empresa tiene que empezar con los resultados deseados y tiene que organizar los recursos de la organización para alcanzar esos resultados. La gestión es el órgano que hará que la institución, tanto si es una empresa, como una iglesia, una universidad, un hospital o un hogar para mujeres maltratadas, sea capaz de producir resultados fuera de sí misma ${ }^{14}$.

Es en este punto donde entra la Comunicación Corporativa a formar parte de la gestión empresarial, como herramienta a su favor, porque tiene unas posibilidades que, hasta ese momento de integrarla en la gestión empresarial, la empresa no había utilizado para la consecución de sus resultados proyectados. Ya que, el interés y la responsabilidad de la gestión es cualquier cosa que afecte al rendimiento de la empresa y a sus resultados, tanto en el interior como en el exterior, tanto si están bajo el control de la empresa o totalmente fuera de ella.

La comunicación de las empresas ha evolucionado hacia una perspectiva estratégica, y se ha incorporado a la gestión empresarial, denominándose Comunicación Corporativa y entendiéndose que el objetivo de esta nueva forma de entender la comunicación es construir una adecuada imagen de la empresa y establecer relaciones de calidad continuas entre ella y sus públicos.

Todas las organizaciones obedecen a una serie de supuestos que especifican qué es la empresa, cuáles son sus objetivos, cómo define sus resultados, quiénes son sus clientes y qué valoran y por qué pagan esos clientes. La estrategia convierte esta teoría de la empresa en rendimiento. El propósito de la estrategia es capacitar a una organización para conseguir los resultados que desea en un entorno impredecible. Porque la estrategia permite que una organización sea «oportunista con un fin determinado ${ }^{15}$. Por eso la Comunicación Corporativa se convierte en estrategia, porque ayuda a la consecución de este fin determinado con un espíritu oportunista, de aprovechar la ocasión, la situación, la coyuntura, la información, la investigación, en cada caso se actuará en función de una determinada situación.

El éxito de un negocio se basa en la creación de valor y riqueza. Esto exige que se tomen decisiones arriesgadas sobre la teoría y la estrategia de la empresa, sobre el abandono de lo viejo y la innovación de lo nuevo, sobre el equilibrio entre la

\footnotetext{
${ }^{14}$ DRUCKER, P. El management del siglo XXI. Edhasa. Barcelona, 2000. Pág. 69.

${ }^{15}$ DRUCKER, P. El management del siglo XXI. Edhasa. Barcelona, 2000. Pág. 72.
} 
rentabilidad inmediata y la cuota de mercado. Exige tomar decisiones estratégicas basada en las certidumbres que se conocen.

El fenómeno que explica esta evolución hacia una nueva posición en la estrategia empresarial es el papel que adquiere la Comunicación Corporativa como apoyo a la estrategia corporativa.

Los objetivos estratégicos no son fijados únicamente por la Alta Dirección, otros actores intervienen en este proceso (individuos, grupos, organizaciones), que mantienen relación directa o indirecta con la empresa y que pueden verse afectados, positiva o negativamente, por las decisiones y/o acciones de la misma. Por tanto, los objetivos de la gestión empresarial no deben estar en conflicto con los objetivos de estos otros agentes, en caso contrario encontrarían problemas en la implementación de la estrategia.

La Comunicación Corporativa sirve para estar comunicados con los diferentes grupos de interés y consigue la visión de la Dirección sea transmitida de forma clara, inequívoca y correcta. Lo que favorece y sirve para la consecución de los objetivos estratégicos marcados.

La comunicación corporativa es precisamente un proceso integral de comunicación que una empresa realiza en cualquier momento del día, tanto de forma consiente como de forma inconsciente. La comunicación Corporativa tiene su origen en la filosofía de la propia empresa, en la imagen que la empresa desea proyectar tanto hacia el interior como hacia el exterior. Erróneamente, la comunicación corporativa ha sido identificada en muchas ocasiones sólo por el logotipo de la empresa o el diseño gráfico que emplea de cara al exterior. Sería un engaño creer que una empresa es identificada por su público sólo por estos elementos. La imagen corporativa de una empresa la forman innumerables componentes, algunos de éstos incluso pueden pasar inadvertidos por parte del público y por parte de la empresa, pero todos deben ser coherentes entre si y cuidados diariamente. La imagen corporativa es uno de sus principales activos.

Un programa de Comunicación Corporativa, entendido como el conjunto de técnicas empleadas para proyectar y cohesionar la imagen interna y externa de una empresa, es una responsabilidad del máximo representante de la empresa ${ }^{16}$.

Todo esto adquiere significado cuando los académicos y profesionales coinciden en que las empresas descubren que su objeto, por encima de fabricar bienes y prestar servicios, consiste en satisfacer demandas de valores intangibles. En la medida en que el progreso económico ha pasado del sector industrial al sector servicios, y además, cuando entre los bienes materiales promovidos por distintas empresas

\footnotetext{
${ }^{16}$ ADECEC. El libro práctico de la Comunicación y las Relaciones Públicas. El porqué y el cómo de una profesión apasionante. Folio. Barcelona, 1997. Pag. 37.
} 
tampoco hay diferencias, el poder de comerciar en el mercado se mide por la capacidad de satisfacer a las personas.

«Y, en el fondo, la satisfacción del demandante no viene tanto por el efecto de la oferta, sino por la acción que la conduce, es decir por la persona u organización que patrocina la relación comercial, ahora los clientes, al expresar su demanda en el mercado, tienen en cuenta los rasgos del producto y la personalidad e la empresa que los ofrece ${ }^{17}$ »

Esto ha contribuido a modificar los sistemas de comunicación y a incluir la dimensión institucional de las organizaciones.

${ }^{17}$ SOTELO, C. Introducción a la comunicación institucional. Ariel Comunicación. Barcelona, 2001. Pág. 8. 